\title{
Effective Strategies to Lead Merging Organizations
}

\author{
Achmad Supriyanto \\ Department of Educational Administration \\ State University of Malang, Indonesia \\ a.supriyanto.fip@um.ac.id
}

\author{
Burhanuddin \\ Department of Educational Administration \\ State University of Malang, Indonesia \\ burhanuddin.fip@um.ac.id
}

\begin{abstract}
This paper describes trends of merging organizations in improving their performance. Research was conducted employing a meta-analysis technique. Literatures and findings from previous studies were reviewed to explore how companies those engaged in the merging context are led. The study focused on key issues determining the success of merger and acquisition. It also identifies indicators for the success of merging organizations, and how leader develop a new culture in the new organizations. Results found that economic condition of companies, market, and global competitions challenge some corporates to merge their companies or organizations. Recommendations and directions for future research are offered by the authors.
\end{abstract}

Keywords: merger, organizational culture, leadership, competitive, market

\section{INTRODUCTION}

Merger organization is a part of study in management science, specifically management of organizational change (Yu \& De Ven, 2005). Global competitions and internal economic condition of companies influenced their capacities to survive within the current position. Many organizations or firms have decided to sell and merge their assets to other companies (Gibson, Ivancevich, Donnelly, \& Konopaske, 2006). Some of the companies involved in the merging line are Chevron Pacific Indonesia (CPI) and Chevron Indonesia Company (CICO). This trend will be stronger approaching ASEAN Bank integration 2020, and most companies have been involved in mergers and acquisitions (M\&A) program as reported during 2015 that have total investment of 1 trillion US dollar (Muliana, 2016). Such decisions were made in order to improve the performance in the future (Mueller, 2003). These attract faculties of higher education institutions and practitioners to examine how the merging program has effectively increased the productivity of the companies (Mueller, 2003). Organizations are expected to become stronger after being merged. Bradt (2015) explained that merging organizations will be more valuable compared to individuals who work separately. It continuously becomes strategic choice for many decision makers, owners, and managers (Bradt, 2015). The reason is that merger is predicted to provide more benefits for most organizations or firms. Bradt (2015) for example suggested a fundamental premise that the merging entities will be more valuable when they are operated as an integrated asset. That is why this strategy has been used as one of strategic alternatives to improve companies business performance within the changing situation (Bligh, 2006).

However, merger frequently failed. Reports indicated $83 \%$ of the merging companies were not successful (Bradt, 2015). "The vast majority of leaders get something very wrong along the way" (Bradt, 2015). Cortina (2015, p. 1) said "despite the increasing popularity of mergers and acquisitions, it has been reported that more than two-thirds of large merger deals fail." The failure of the merging programs was assumed to be triggered by disregarding the importance of organizational culture (Michelle C. Bligh, 2006; Cortina, 2015)

Despite the failures of some merger companies, it does not mean that the merging programs will be stopped. Management specialist and practitioners analyse the conditions influencing the effectiveness of the merging programs, and develop strategies have been explored to improve the performance of merging organizations continuously. It is evident that the success of some merger organizations is determined by: (1) the specific value that will be created from the merger, (2) fully integrate the two businesses, and (3) ensure cultural compatibility (Bradt, 2015). The determinant factors are conceived to organizational culture variable. Such conditions noted by the researchers, and used as input in the meta-analysis process of this study. How the integration of new culture into new institutions is examined to formulate the appropriate strategies in improving the merging performance in the future.

\section{THEORETICAL FRAMEWORK}

\section{Merger and Acquisition in Practice}

The forms of inter-organizational encounter are characterised by the two phenomena of Merger and acquisition (M\&A). Both are used for different purposes. Conceptually, merger is defined as a combination of two or more organisations or companies to a new entity synergically (Morresi \& Pezzi, 2014). Within a long term program, the merger organizations are predicted to be more stronger compared with the condition before they are merged.

Theoretically, mergers between two or more entities result in synergic business among the participating companies. The participants of this merger program can establish or create and sustain added values continuously that concern the increased business performance (Schlachter \& Hildebrandt, 2017). Such synergic business can be noted as 1 plus $>$ 2. Not 1 plus $1<2$. (Kiryanto, 2002; Ratnawati \& Dewi, 2005). An overview of conceptual differences between mergers and acquisitions is presented in the following Figure 1. 


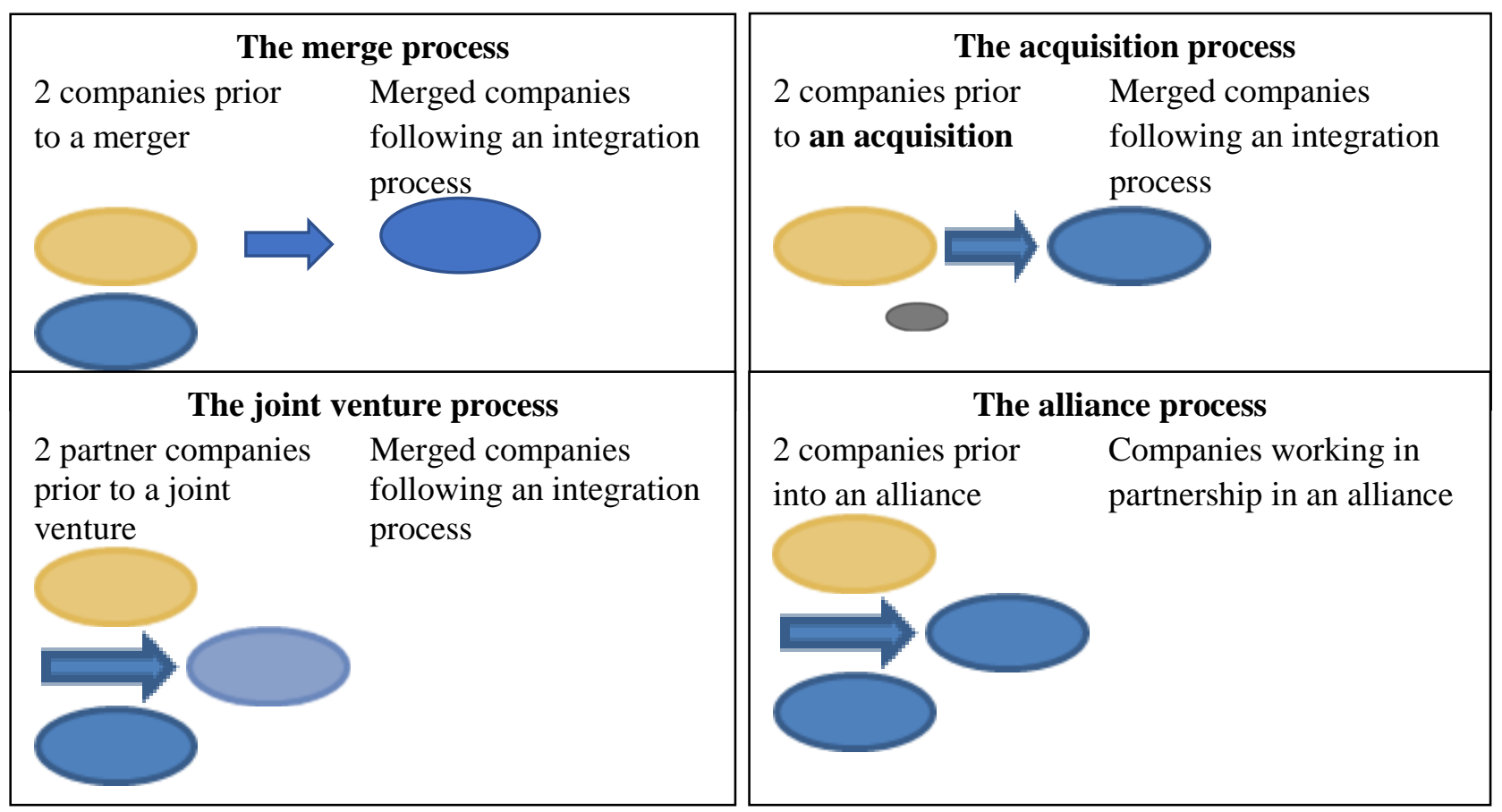

Figure 1

Conceptual Differences Between Mergers And Acquisitions (Source: Teerikangas in Cooper, 2007)

Specifically, these forms of interorganizational encounter have different purposes in their implementation. However, both can represent the similarity where two organizations merge to a greater or lesser degree following the closing of the deal. Since the interpretation of the two concepts sometime overlap, it is difficult to set their clarity. For the purpose of study, merger is highlighted as an effort to combine two separate companies or organizations, and these two or more companies are led to join a new and legal organizational identity (Teerikangas, 2007).

Principally, merger integrates two or more organizations into one company (Morresi \& Pezzi, 2014). In contrast, acquisition is regarded as the managerial accomplishment of one company to buy a part of other companies. Depending on the integration approaches applied, the firms that buy the other assets will begin to run the acquired company as a part of their operations in full or partially. In the case of a full integration as intended by previous companies, merger and acquisition will be considered as exposing managerial similarities and challenges (Teerikangas, 2007).

\section{Merger Objectives}

Merger has objectives: (1) strengthen capital structure; (2) improve capital structure, (3) improve the sustainability against the risks of post-merger program for banking system, and improve competitive capacity. This enhances the banks position in domestic and overseas. Followed by expanding the reach of customers which results in a broad segment of customers and improves the capital from third resource. It can also increase capacities in offering credits to customers. Hence, income of bank interest increases. Merger increases the variety of bank products based on the business excellence of the companies. Finally, in terms of stakeholders and the government, merger may improve revenues from tax dividend, and cash when the post-merger is devastated (Kiryanto, 2014; Schlachter \& Hildebrandt, 2017). De Camara \& Renjen (2004) in "The Secret of Successful Mergers: Dispatches from the front lines" outlined that merger activities will be continuously synergic, and its integration become a hot topic of the executives.

\section{Effects of Merger}

Merger as strategy is used by many organizations. A few years ago many companies participated in this program. They experienced more benefits compared to previous condition before being merged (Schlachter \& Hildebrandt, 2017). Some research studies indicated that the merging programs improve the performance of companies in terms of the increased financial benefits, efficiency, market expansion, and production capacity in the future (Teerikangas, 2007). Studies of post-merger share performance found that mergers were not succeeded by long declines in returns to the buyers or acquirers. This happened at some points of time of the merging program. Further, when the stock market is not at the best condition, mergers tend to be successful (Müller \& Turner, 2010).

However, other some studies showed that the merger banks experienced unsatisfied results. They had negative effects on financial performance. The reasons probably are that mergers were conducted without considering non-technical aspects in particular human resource issues (Supriyanto, 2008). Specifically, this relates with the integration process of organizational culture into new organizations (Michelle C. Bligh, 2006). Such a phenomenon becomes an attention to 
this study to examine how the integration process (Christian Homburg \& Matthias Bucerius, 2006) in the merging programs is determined by the effectiveness of organization culture integration into the new companies at post-merger time.

\section{METHODS}

This research uses a meta-analysis model that integrates resources of investigations through multiple findings of scientific research studies. Basic assumption of this procedure is that there is a common truth generated from relevant studies where a certain error of the respective studies is estimated. To derive the pooled estimates that are close to unknown common truth, certain statistics approaches were used.

Meta-analysis is able to compare results from some studies, identify patterns of findings among the studies, differences, sources of those results, and relationships that come up from the multiple studies (Oxford, 2017). The subjects included in this study were studies from articles, book chapters, and other related published works concerning the merging organizations program. The major requirements for inclusion were both quantitative and qualitative data from current studies reported in scientific results including journals, books, or other published works.

\section{RESULTS}

Research findings indicate five critical issues surrounding the success of mergers and acquisitions for most organizations participating in this program (Cornett \& Friedman, 1995 ). Roberta Hill et. al. (2008) highlighted five critical issues that have to be considered in the merger program. These include: (1) time, (2) top down \& bottom up focus, (3) identity, (4) communication, and (5) quality. How corporation leaders put their energy on developing time and vision that foster and promote staff motivation and participation. What sorts of strategies employed to improve the effectiveness of the post-merger. The single and important factor in supporting post-merger success is staff participation. This has to be implemented from the beginning to the stage of identity creation in referring to a shared vision.

Learnt from successful merger, the findings of Hill et. al. (2008) identified seven steps implemented in the merging program including: (1) members participation as promoted by leaders, (2) create and develop shared vision, (3) context analysis to assess the reality of current condition based on companies strategies, (4) actions in supporting the process through building a sense of belonging during the merging activities, (5) implementation in building and creating the right momentum of the merging process, (6) maintenance, which suggest leaders to focus their attention on the direction of new merger and energy of new companies identity, and (7) renewal, that leaders evaluate results and end the program through providing restoration time.

On the other hand, the success of mergers was determined by many factors (Cornett \& Friedman, 1995 ). Specifically this success is influenced by the strategies of leaders in managing organizational cultures adopted in the new merged companies. Leaders are challenged to make strategic decisions during mergers. Many decisions that are generally driven by strategic and financial considerations. But quite many companies participating this merger and acquisition failed to meet their expectations because strategies employed in the post-merging stage are incompatible with the partners' culture (Cartwright \& Cooper, 1993). Research indicated that in many companies included in the merger programs, some strategies as well as financial decisions made was definitely incompatible with the context or culture of those companies. This has been claimed as one of the factors contributed consistently to the high rate of failure in the merger and acquisition programs. In order word the selection of a suitable approach to managing organizational culture is inappropriate (Michelle C. Bligh, 2006; Cartwright \& Cooper, 1993).

How to pave the road to merger excellence while evading the faults? Clear guidelines and process are required at each merger or acquisition stage. At each phase of merger or acquisition, a pre-merger process that targets companies which has a good cultural match, will get compatible values that are in line with the achievements of corporate strategies. This begins the integration through rigorous, yet flexible collaborative planning and trust-building. It enables the two companies move towards an engagement culture, involving companies' stakeholders from the beginning of the merger.

A pre-merger process that targets companies that are a good cultural match, have compatible values and are in line with achieving corporate strategy. This begins the integration through rigorous, yet flexible collaborative planning and trust-building. It enables the two companies to move towards a culture of engagement, involving stakeholders from both companies at the start of the merger.

A merger process for creating a Shared Vision that can be owned at each level of the organization and readily expanded into an integrated strategy (Christian Homburg \& Matthias Bucerius, 2006). It is formulated to support and define where the new company is going and communicate how the formation of this new company fits the overall vision. This sets the base for a new identity and a perfect corporate brand.

A post-merger process is a phase within which time and people become valuable resources to support the collaborative process in the merging program. Communication is supposed to be open and transparent. Integration teams are comprised of members from companies run by various stakeholder groups. Such a process will reinforce main competencies, build a forward momentum and implement a collaborative, flexible methodology for consolidation. Identification employing New Identity becomes realty.

Studies that were reported by Bird (2015) show that in the global companies such as $\mathrm{P} \& \mathrm{G}$ (Procter \& Gamble, a manufacturing sector company), companies are lead in the ways not just to maintain the balance between the two alternatives (flexibility of methodologies \& collaborative approach), but lead 
through incorporating multi paces of cultures that embedded in the diverse organizations specifically from about 80 national cultures around the world. The suspended spider is automatically created from this tightrope impact. Leaders of the merger companies (Bird, 2015) experienced this phenomenon in their acquisition of assets. In order to keep self-corrected and balance, at least four methods were used:

Decategorize. Members of the in-group have a tendency to regulate members of the out-group. This situation happens when there have been contacts without having attention to the diversity and differences within the out-group. When contacts happen in a situation like an acquisition and in-groups and out-groups form. To improve the merging program, leaders need to structure the relations or contacts within the merging organizations so that people in-group and out of group must treat one another as individuals (Christian Homburg \& Matthias Bucerius, 2006). P\&G leadership took great efforts to create integration teams composed of both groups who must work on shared tasks, thus forcing them to personalize their interactions and focus on specific and shared goals

Recategorize. Through establishing a new larger group, leaders of the mergers organization can overcome in and out-group biases. This is implemented by developing a superordinate category for both groups. Such a procedure enables preservation for their associated attributes and cultural identities. However, to create as a new "We" is a challenge to many managers. As a result, in the case of $P \& G$ companies described above, executives of these companies didn't rename itself, but they used other forms of the recategorizations.

Mutual differentiation. Identifying complementarities and structuring group relations. As a division of labour in services of a common goal, two related groups may be identifiied for being restructured in to a similar division. While preserving the original identities, in the process, in-group restructuring develop positive attitudes toward the out-groups. In the case of French marketing and advertising agency as a public group for example, the preserved acquired agency of this company identified the new organizations by reconceptualising their relationships as parts of a family. The company like Gillette that had a merchandising expertise, this company complemented P\&G's branding acumen. Gillette's focus on male consumers complemented P\&G's expertise in female consumers. However, leaders must concern on the effects of such procedures. The families that may elbow and sometimes fight one another. But in the end they are aware as a family and help one another.

\section{The Success of Mergers and Acquisitions}

Findings of the studies by Carleton and Lineberry (2004) focusing on the success of merger and acquisition lead to key points of the samples of ways to measure post-merger or integration success financially and culturally as they listed in the following.

\section{Financial Success Measures}

For the purpose of monitoring programs in assessing organizational performance following merger or acquisition, data on the following measures are routinely collected by the finance, legal, and HR departments. Results were summarised listing the key indicators of the success obtained by the $M$ \& $A$ programs including: increase or decrease in share price, revenue, operating profit; profitability, payback of capital costs, recovery of paid premiums, productivity, market share, loss of key staff and executives.

\section{Cultural Integration Success Measures}

On behalf of to determine the progress and status of the cultural integration of two companies after a merger (Christian Homburg \& Matthias Bucerius, 2006), the following measures can be used including (1) Web-Based CDD Re-Survey-assuming an initial CDD survey was conducted in conjunction with cultural due diligence, targeted samples or the total staff can be re-surveyed at about the mid-point of the integration effort and the results compared to those of the initial survey; (2) Web-Based Staff Opinion/Attitude Survey - targeted or all-staff sampling at intervals to quantify staff's perceptions of and satisfaction with the current integration activities; (3) Web-Based 360Degree Leadership and Management Surveyassuming an initial 360-degree survey was conducted of all managers and leaders and the organization on the behavioural leadership practices that support each of the organization's core values, follow-up surveys provide individual and collective data on how well the core values and practices are being modelled; (4) Monitoring for the Customer Service Levels and Customer Satisfaction-assuming such measures currently exist. Variations from both service level and customer satisfaction can be monitored. Effective cultural integration will be reflected in initial maintenance of current levels, with a trend upward in both measures as the integration proceeds; (5) "Listening Posts" and Focus Groups-people within various business units and functions can be assigned "listening post" duty to informally; (6) Focus Groups/Surveys and Customer Interviews were used. These were carried out assuming full communication to customers about the rationale for the merger and expected benefits. Focus groups, interviews and surveys can be conducted with key customers to assess their perspectives on the merger and how it is played out in the marketplace; and (7) Focus and Monitoring of Current Organizational Measures-specific focus on and monitoring of current measures of productivity.

\section{DISCUSSION}

Values, beliefs, cultural norms may inevitably conflict to each other. Such a condition could happen in the post merging program. The value for hierarchy for example potentially contradict the process of consensus decision-making and egalitarian interactions against decision rights that are clearly demarcated. In some cases that were found in organizations, leaders highlighted the importance both consensus decision- 
making and demarcated decision rights. Some companies practised both of these effectively.

Management of organizational culture in the merger organizations depends on the ability to comprehend when, and how leaders identify and treat or manage the culture for the benefits of the companies' organizations (Morresi \& Pezzi, 2014). However, too much emphasis on the differing elements may cause managers unaware on the commonalities among the groups. But, at the same time it is easy to assume that people will have a simple and universal way to identify them as human being. As a native person from Hyderabad sitting in Cincinnati, Nagrath developed this sensitivity (Bird, 2015). The managerial art lies in developing the awareness to differences without paying undue attention to these differences. Whether leaders integrating a culturally diverse team or adapting a product for a new market, the key is the balance - and to self-correction before those leaders fail.

Organizations that were built based on a shared vision and understood by people can improve significantly participation spirit. This finding is in line with experiences demonstrated by successful mergers. The process of successful merger and acquisition is characterised by a comprehensive integration process, open communication, flowing and has been done effectively.

The management success of organizational culture should be perceived as an art of leadership that is grounded by judgment. It hinges on balance as a tightrope act. Following a statement of famed French high wire walker, Philippe Petit (Bird, 2015; Carleton \& Lineberry, 2004), this is about looking for selfcorrection and revolving it into an art. In global merger organizations, it is not just about maintaining the balance between two alternatives, but doing so while leading a sprawling organization across multi-national cultures involving many countries.

Findings indicated that many merger programs failed during the post-merger or acquisition. These were mostly caused by inappropriate strategies applied by managers (Epstein, 2005). Over the last twenty years research concerning the success of thousands of mergers and acquisitions-large and small-shows that between 55 percent and 77 percent fail to deliver on their intended financial benefits (Carleton \& Lineberry, 2004). Most acquiring firms really lose their money on those acquisitions. Results of research studies also shows that this is mainly due to the failure to effectively assess and integrate the organizational cultures of the companies involved in merger or acquisition projects. The high rate of such failures and their significant costs are of increasing as suffered by the stakeholders of companies involved. They were not just the boards of directors and executives who make the deal, but these were also experienced by all employees, customers, shareholders, community residents, and suppliers.

\section{CONCLUSION}

In conclusion, effective merging program is improved significantly through creating a shared vision of the organization. This stage can be used to make people in the new companies are being engaged in the process and develop strategies to make the post merging activities success. Merger organizations have to introduce people with the new culture that has been established before the new companies were created. Leaders and managers are necessary to develop the culture that supports positive and conducive environment for people who work in the new companies. Members of the organizations are encouraged to improve culture in order to anticipate changes in the future. Leaders must concern some determinant factors that may influence the performance of the post merging program. Research studies are expected to be carried out in the future in order to formulate comprehensive conclusions. The studies are designed to include the investigations concerning broader factors or variables.

\section{REFERENCES}

[1] Bird, M. 2015. Merging Two Global Company Cultures. Harvard Business Review, August 4.

[2] Bligh, M. C. 2006. Surviving Post-merger 'Culture Clash': Can Cultural Leadership Lessen the Casualties. Leadership, 2, 395.

[3] Bradt, G. 2015. The Root Cause Of Every Merger's Success Or Failure: Culture. .

[4] Carleton, R., \& Lineberry, C. S. 2004. Achieving Postmerger Success. A Stakeholder's Guiode to Cultural Dute Deligence, Assessment, and Integration. San Francisco, CA: Pfeiffer.

[5] Cartwright, S., \& Cooper, C. L. 1993. The Role of Culture Compatibility in Successful Organizational Marriage. Acad Manage Perspect, 1, 57-70.

[6] Cornett, M. M., \& Friedman, D. P. G. 1995. Communication Processes and Merger Success: An Exploratory Study of Four Financial Institution Mergers Management Communication Quarterly, 9(1).

[7] Cortina, C. 2015. The Role of Organizational Culture in Mergers and Acquisitions Management Consultant at amg Consulting. Retrieved January 27, 2018, from https://www.linkedin.com/pulse/role-organizationalculture-mergers-acquisitions-cecilia-cortina.

[8] De Camara, D., \& Renjen, P. 2004. The Secret of Succesful Mergers: Dispatches from the Front Lines. Journal of Business Strategy, 25(3).

[9] Epstein, M. J. 2005. The Determinants and Evaluation of Merger Success Business Horizons, 48(1), 37-46.

[10] Gibson, J. L., Ivancevich, J. M., Donnelly, J. H. J., \& Konopaske, R. 2006. Organizations: Behavior, Structure, Processes. Boston: McGraw-Hill/Irwin.

[11] Hill, R., Weiner, S., \& Weiner, S. 2008. Seven Steps to Merger Excellence. Ivey Business School Western University Canada (September/October).

[12] Homburg, C., \& Bucerius, M. 2006. Is Speed of Integration Really a Success Factor of Mergers and Acquisitions? An Analysis of the Role of Internal and External Relatedness. Strategic Management Journal, 27, 347-367

[13] Homburg, C., \& Bucerius, M. 2006. Is Speed of Integration Really a Success Factor of Mergers and Acquisitions? An Analysis of the Role of Internal and External Relatedness. Strategic Management Journal, 27, $347-367$.

[14] Kiryanto, R. 2014. Konsolidasi Perbankan: Wacana Merger Mandiri-BNI Bergulir, Ini Tanggapan BNI. Finansial. Retrieved January 12, 2018, from 
http://finansial.bisnis.com/read/20140503/90/224323/in i-penjelaskan-bni-soal-wacana-merger-dengan-mandiri-

[15] Morresi, O., \& Pezzi, A. 2014. Cross-Border Mergers and Acquisitions. Theory and Empirical Evidence. New York: Palgrave Macmillan.

[16] Mueller, D. C. 2003. The Corporation: Investments, Mergers and Growth. London: Routledge.

[17] Muliana, V. A. 2016. Daftar Merger dan Akuisisi Terbesar Sepanjang 2015 (List of Merger and Acquisition. Retrieved January 12, 2018, from http://bisnis.liputan6.com/read/2400324/daftar-mergerdan-akuisisi-terbesar-sepanjang-2015

[18] Müller, R., \& Turner, R. 2010. Leadership Competency Profiles of Successful Project Managers. International Journal of Project Management, 28(5), 437-448.

[19] Oxford, U. O. 2017. What is a Meta-Analysis? Centre for Evidence Based Intervention (CEBI). Retrieved January 12, 2018, from https://www.cebi.ox.ac.uk/forpractitioners/what-is-good-evidence/what-is-a-metaanalysis.html.

[20] Supriyanto, A. 2008. Pengaruh Merger terhadap Respons Sikap, Adaptasi Diri, Komitmen Kerja, Integrasi Budaya Kerja, dan Kinerja Pegawai Bank (Studi pada Beberapa Bank Hasil Merger di Kota Malang). Universitas Brawijaya Malang, Malang.

[21] Teerikangas, S. 2007. A Comparative Overview of the Impact of Cultural Diversity on Inter-Organisational Encounters. In C. L. Cooper \& S. Finkelstein (Eds.), Advances in Margers and acquisitions (Vol. 1-5, pp. 37-70). Amsterdam: Elsvier.

[22] Yu, J., Engleman, R. M., \& De Ven, A. H. 2005. The Integration Journey: An Attention-Based View of the Merger and Acquisition Integrationprocess. Organization Studies, 26(10), 1501-1528. 